\title{
Dietary Factors and Risk of Advanced Prostate Cancer
}

\author{
Wambui G. Gathirua-Mwangi ${ }^{1}$ and Jianjun Zhang ${ }^{1,2}$ \\ ${ }^{1}$ Department of Epidemiology, Richard M. Fairbanks School of Public Health, Indiana University, \\ Indianapolis, Indiana, USA \\ ${ }^{2}$ Indiana University Melvin and Bren Simon Cancer Center, Indianapolis, Indiana, USA
}

\section{Abstract}

Objective-Prostate cancer is the second most common cancer among men in the world. Although some nutrients have been linked to the development of total prostate cancer, it remains unclear whether these nutrients modulate the risk of its clinical significant form - advanced tumor. Therefore, this study sought to perform a systematic review of the literature on this topic.

Methods-The papers reviewed were identified from PubMed by searching key words, diet and advanced, metastatic, or lethal prostate cancer. A total of 46 papers published until September 2012 met our eligibility criteria and thus were evaluated in this review.

Results-Epidemiologic studies have overall showed that the habitual consumption of a diet high in saturated fat, well-done meats, and calcium is associated with an increased risk of advanced prostate cancer. An inconsistent association was observed for intakes of total meat, fruits, and vegetables. Although most case-control studies suggest that intakes of these nutrients or foods significantly alter advanced prostate cancer risk, cohort studies yielded mixed results. No apparent effect of fish and zinc intake on advanced prostate cancer was found in most epidemiologic studies.

Conclusions-Epidemiologic studies conducted to date have revealed that some dietary factors modulate the risk of advanced prostate cancer. If these findings are confirmed by more adequately-powered epidemiologic studies, especially prospective cohort studies that measure the nutrients and their biochemical indicators, the risk of advanced prostate cancer, which is fatal and thus clinically significant, may be reduced by dietary modification or chemoprevention.

\section{Keywords}

diet; advanced prostate cancer; epidemiology; prevention

\section{Introduction}

Prostate cancer is a leading cause of cancer death in most developed countries and an emerging public health problem in developing countries (Jemal et al., 2011). On the global level, prostate cancer is the second most commonly diagnosed cancer and the sixth leading

Address for Correspondence: Jianjun Zhang, MD, PhD, Department of Epidemiology, Richard M. Fairbanks School of Public Health, Indiana University, 714 N Senate Avenue, Suite EF 209, Indianapolis, IN 46202, Phone: (317) 274-4287, Fax: (317) 274-3443, jz21@iupui.edu. 
cause of cancer death among men (Jemal et al., 2011). To date, however, the etiology of this malignancy remains unclear, with age, race, and family history as the only well-established risk factors (Hsing and Devesa, 2001; Leitzmann and Rohrmann, 2012).

Ecologic and migrant studies have offered substantial evidence that dietary factors may play a role in the etiology of prostate cancer (Rose et al., 1986). Specifically, populations with high intake of saturated fat and red meats have an increased risk of prostate cancer compared with populations with low intake of these nutrients or food items (Ma and Chapman, 2009; Michaud et al., 2001; Rose et al., 1986). Remarkable increase in the risk of this disease has been observed after men in East Asia immigrated to North America (Whittemore et al., 1995). Prostate cancer incidence rates have been rapidly increasing in China, Korea, Japan, and Singapore during the last several decades (Zhang et al., 2012). This upward change has been primarily ascribed to the occurrence of nutrition transition in these countries during the same period of time (Zhang et al., 2012). Nutrition transition is defined by a gradual change towards the Westernized diet characterized by high intake of energy, animal fat, and meats and low intake of fiber (Zhang et al., 2012). Although aforementioned descriptive epidemiologic studies suggest that dietary habits influence the risk of prostate cancer, casecontrol and cohort studies have provided mixed results on dietary etiology of this malignancy (Michaud et al., 2001; Zhu et al., 2005).

Prostate cancer can be either indolent or aggressive. While indolent tumors may remain asymptomatic for a whole life, aggressive tumors can rapidly progress to advanced disease (Brassell et al., 2011). A growing body of evidence suggests that these two types of prostate cancer have a different etiology (Rose, 1997). One of the potential reasons for inconsistent results of case-control and cohort studies examining the association between diet and prostate cancer may be that most of these studies had a small number of advanced tumors. Given the clinical importance of advanced prostate cancer, it is crucial to understand which nutrients, foods, or food groups significantly modulate the risk of its occurrence. Therefore, this paper sought to review the current evidence of epidemiologic studies on this topic.

\section{Materials and Methods}

A PubMed search of published papers was conducted through September 2012 to identify studies eligible for review. A total of 280 papers were found when keywords 'diet' and 'advanced prostate cancer'; 'diet' and 'lethal prostate cancer'; and 'diet' and 'metastatic prostate cancer' were used. A paper was eligible for review if it reported separate risk estimates [odds ratio (OR) or relative risk (RR)] for advanced, lethal, or metastatic prostate cancer. The abstracts of all these papers were reviewed to determine whether they met the inclusion criteria. When an abstract did not provide sufficient information for this eligibility evaluation, its full paper was examined instead. Studies were excluded if they were published as a review paper or reported in the form of an abstract only. To ensure the adequacy of published data for review, we only examined the nutrients, foods, or food groups that have been investigated in relation to risk of advanced prostate cancer in at least three independent studies. The nutrients, foods, or food groups that met this criterion are meat and meat products, fat, calcium, dairy products, fruits and vegetables, lycopene, vitamins, fish, zinc, and dietary patterns. 
The following information was extracted from each of eligible papers: author(s), publication year, study population, study design, geographical location, sample size, dietary assessment methods, risk estimates [(OR or RR) and 95\% confidence intervals $(95 \% \mathrm{CI})]$, and confounders controlled for in multiple regression analysis. If more than one paper was published using data collected from the same study, the paper that analyzed most recent data or had the largest (or larger) sample size was included in this review.

\section{Results}

The dietary factors reviewed for their associations with the risk of advanced prostate cancer included meat and meat products (Table 1), fat (Table 2), calcium, vitamin D, and dairy products (Table 3), fruits, vegetables, and vitamins (Table 4), lycopene and tomato products (Table 5), and fish and other dietary factors. Lycopene abounds in tomatoes and tomato products (Giovannucci, 1999). The results of epidemiologic studies evaluating the effects of tomatoes and tomato products on advanced prostate cancer were presented in a separate table because a large number of studies have investigated this association. The results shown in all tables are risk estimates (ORs or RRs) comparing the highest with the lowest intake categories of nutrients or foods.

\section{Meat and Meat products}

Case-Control Studies-Most case-control studies showed inconsistent associations between meat intake and the risk of advanced prostate cancer, whereas the promoting effect was overall consistent across studies for intakes of well-done meats and suspected carcinogens derived from the meats cooked in this manner (Table 1). In a population-based case-control study, total meat and white meat consumption was not associated with the risk of advanced prostate cancer (John et al., 2011), but a significantly progressively elevated risk of advanced prostate cancer were observed for higher intake of hamburgers ( $\mathrm{p}$-trend = 0.02) (John et al., 2011). In another study, intake of red meat, hamburger, steak, poultry, sausage, processed meat and bacon did not alter advanced prostate cancer risk (Joshi et al., 2012).

A number of suspected mutagens or carcinogens are produced when meats are cooked at high temperature (Gu et al., 2010; Sinha et al., 1998; Sugimura et al., 2004). Depending on the types of meat and level of doneness, the mutagens detected in cooked meat include: heterocyclic amines [e.g. 2-amino-1-methyl1-6-phenylimidazo[4,5-b]pyridine (PhIP), 2amino-3,8-dimethylimidazo-[4,5-b]quinoxaline (MeIQx), and 2-amino-3, 4,8trimethylimidazo-[4,5-f]quinoxaline (DiMeIQx), and polycyclic aromatic hydrocarbons [e.g. benzo(a)pyrene (BaP)] (Gu et al., 2010; Sinha et al., 1998; Sugimura et al., 2004). One study has demonstrated a marginally significant association between PhIP intake and the risk of advanced prostate cancer [OR $(95 \% \mathrm{CI}): 1.2(0.9,1.6)$, for quintile 5 vs. quintile 1] (Joshi et al., 2012). In addition, intakes of red meat [OR (95\% CI): $1.4(1.0,1.9)$, for quintile 5 vs. quintile 1 , p-trend $=0.026$ ] and hamburger [OR $(95 \% \mathrm{CI}): 1.7(1.3,2.2)$, for quartile 4 vs. quartile $1, \mathrm{p}$-trend $=<0.001$ ] cooked at high temperature, well-done red meat [OR $(95 \%$ CI): $1.4(1.1,1.8)$, for quartile 4 vs. quartile 1 , p-trend $=0.013$ ], and pan-fried red meat [OR (95\% CI): $1.3(1.0,1.8)$, for quartile 4 vs. quartile $1, \mathrm{p}$-trend $=0.035]$ were found to increase 
the risk of advanced prostate cancer (Joshi et al., 2012). These results were confirmed by a study in which an increased risk was observed for high intakes of grilled beef, well-done beef, and well-done hamburger (Punnen et al., 2011). In addition, intake of MelQx [OR (95\% CI): $1.69(1.08,2.64)$, for quartile 4 vs. quartile 1 , p-trend=0.02] and DiMelQX [OR (95\% CI): $1.53(1.00,2.35)$, for quartile 4 vs. quartile 1 , p-trend $=0.005]$ were associated with an elevated risk of aggressive prostate cancer (clinical stage III/IV tumors or Gleason score 27 ) (Punnen et al., 2011). However, Amin et al, found no association for intakes of red meat, ham and sausage (analyzed as one group), and chicken with the risk of aggressive prostate cancer (Amin et al., 2008).

Cohort Studies-Cohort studies conducted to date overall revealed a modest, inconsistent association between intake of meat and meat products and the risk of advanced prostate cancer (Table 1). Total meat consumption was weakly associated with a significantly reduced risk of advanced prostate cancer in one study (Koutros et al., 2008). An inverse but insignificant association was detected between intake of total unprocessed red meat and the risk of lethal prostate cancer (Richman et al., 2011).

Although the results on the associations of red or white meat consumption with advanced prostate cancer risk were conflicting, most studies suggested that high intakes of meats cooked at high temperature significantly increased risk (Cross et al., 2005; John et al., 2011; Koutros et al., 2008; Sander et al., 2011; Schuurman et al., 1999; Wright et al., 2011). Intakes of red meat, processed meat, heme iron, nitrite/nitrate (derived from meat, grilled or barbecued meat), and B[a]P conferred an elevated risk of advanced prostate cancer in one study (Sinha et al., 2009). However, dietary iron was not associated with the risk of advanced prostate cancer in another study (Choi et al., 2008). It has been also reported that intake of well-done meat was associated with an approximately two-fold increased risk of advanced disease in a dose-response manner [RR (95\% CI): $1.97(1.26,3.08)$, for tertile 3 vs. tertile1, p-trend 0.004) (Koutros et al., 2008). Increased risk associated with consumption of very well done or strongly browned meat was not statistically significant in other studies (Cross et al., 2005; Sander et al., 2011). Hamburger intake was not associated with risk of advanced prostate cancer (Koutros et al., 2008). In addition, intakes of PhIP, MeIQx, and DiMeIQx did not significanlty influence the risk of advanced prostate cancer in a European study (Sander et al., 2011).

The effect of total protein intake was examined but no significant association was found with the risk of advanced prostate cancer, and null results were also obtained for the association between intakes of animal, dairy, and plant proteins and the risk of advanced prostate cancer (Allen et al., 2008). Liver intake was significantly associated with a reduced risk of advanced prostate cancer [RR $(95 \% \mathrm{CI}) ; 0.79(0.63,0.99)$, for quartile 4 vs. quartile 1] in a Dutch study (Schuurman et al., 1999).

\section{Fat}

Case-Control Studies-Case-control studies have consistently revealed that intake of total fat and particularly saturated fat was significantly associated with an increased risk of advanced prostate cancer (Bairati et al., 1998; De Stefani et al., 2000; Slattery et al., 1990; 
Whittemore et al., 1995) (Table 2). Dietary intake of monounsaturated fat (Bairati et al., 1998; De Stefani et al., 2000), polyunsaturated fat (Agalliu et al., 2011; Bairati et al., 1998), linoleic acid, and linolenic acid (Bairati et al., 1998; De Stefani et al., 2000) were generally not associated with advanced prostate cancer risk. When the type and source of linolenic acid were considered, a-linolenic acid and linolenic acid from animal sources (De Stefani et al., 2000) were positively and significantly associated with advanced prostate cancer risk. Higher intake of animal fat was positively associated with the risk of advanced prostate cancer (Bairati et al., 1998; Hayes et al., 1999), whereas a borderline inverse association was observed for total vegetable fat [OR $(95 \% \mathrm{CI}): 0.58(0.32,1.03)$, for quartile 4 vs. quartile 1] (Bairati et al., 1998).

Cohort Studies-To our knowledge, only one cohort study has examined fat intake in relation to the risk of advanced prostate cancer. Phytanic acid is a saturated fatty acid present predominantly in red meat and dairy products. Higher phytanic acid intake was associated with an elevated risk of advanced prostate cancer [RR (95\% CI): $1.38(1.02,1.89)$ for quartile 4 vs quartile 1] (Wright et al., 2011).

\section{Calcium, Vitamin D, and Dairy Products}

Case-Control Studies-Dairy products are rich sources of calcium and vitamin D (Rowland et al., 2011). At the time this review was prepared, only one case-control study had investigated the association between calcium intake and advanced prostate cancer risk (Table 3). High calcium intake was associated with an over two-fold increased risk of advanced prostate cancer [OR $(95 \%$ CI): $2.08(1.22,3.53)$ for quartile 4 vs. quartile 1) (Rowland et al., 2011). Similar results were obtained when total intake of calcium from both diet and supplements was used in the analysis (Rowland et al., 2011). No association was found between intake of dairy products and the risk of advanced prostate cancer (Amin et al., 2008).

Cohort Studies-While most cohort studies suggested that high calcium intake increased the risk of advanced prostate cancer, the effects of milk and other dairy products on aggressive prostate tumors were inconsistent across those studies (Table 3). Schuurman et al., reported no association between intake of milk and milk products and the risk of advanced prostate cancer (Schuurman et al., 1999). However, a significant positive association with calcium intake was observed in another study [RR (95\% CI); 1.62 (1.08, 2.43), for quartile 4 vs. quartile] (Wright et al., 2011). This finding was confirmed by a large cohort study (Giovannucci et al., 1998). In the latter study, high calcium consumption significantly increased the risk of advanced prostate cancer [RR (95\% CI): $2.97(1.61,5.50)$, for $\geq 2,000 \mathrm{mg} /$ day vs. $<500 \mathrm{mg} /$ day intake, p-trend $=0.002$ ] (Giovannucci et al., 1998). In a prospective cohort study in which 1,426 cases of advanced prostate cancer was accrued during 6-years of follow-up, a positive but insignificant association was observed between total calcium intake and advanced prostate cancer (Park et al., 2007). Two other studies did not reveal the positive association of total calcium and dietary and supplemental calcium with the risk of advancced prostate cancer (Ahn et al., 2007; Allen et al., 2008). 
The associations of other dairy products with the risk of advanced prostate cancer was also evaluated in many studies. Skim milk was associated with an elevated risk of advanced prostate cancer [RR $(95 \% \mathrm{CI}): 1.23(0.99,1.64)$, for $>2,000 \mathrm{mg} /$ day vs $<500 \mathrm{mg} /$ day intake, p-trend $=0.01$ ] (Park et al., 2007). However, intake of low-fat milk did not alter the risk of advanced prostate cancer (Schuurman et al., 1999) or even reduced risk (Wright et al., 2011). In a Dutch population, significant positive association was detected between intakes of butter and cheese and the risk of advanced prostate cancer (Wright et al., 2011). In the Prostate, Lung, Colorectal, and Ovarian (PLCO) Cancer Prevention Trial, intakes of total dairy, low fat dairy, and high fat dairy products did not influence the risk of aggressive prostate cancer (Ahn et al., 2007). Furthermore, intakes of calcium from dietary and supplemental sources did not alter the risk of aggressive prostate cancer (Ahn et al., 2007). In only one study, the association between vitamin D and advanced prostate cancer was examined, with null results reported (Giovannucci and Clinton, 1998).

\section{Fruits, Vegetables, and Vitamins}

Case-Control Studies-A few case-control studies have reported an overall inverse association between intakes of fruits and vegetables and the risk of advanced prostate cancer (Table 4). Kolonel et.al. reported that intake of all vegetables were associated with a 33\% reduced risk of advanced prostate cancer (Kolonel et al., 2000). This protective effect was confined to yellow-green vegetables, cruciferous vegetables, and carrots (Kolonel et al., 2000). Intake of fruits did not modulate the risk of advanced prostate cancer (Kolonel et al., 2000). When aggressive prostate cancer was considered, only leafy vegetables [OR (95\% CI): $0.66(0.46,0.96)$, for quartile 4 vs quartile 1 , p-trend $=0.02$ ] were found to be protective (Hardin et al., 2011). Intake of all vegetables, carotenoid-rich vegetables, all fruits (excluding juice), and vitamin $\mathrm{C}$ were marginally significantly associated with a reduced risk of aggressive prostate cancer (p-trend $=0.04$ for all vegetables) (Hardin et al., 2011). However, the aforementioned potential benefits conferred by vegetable consumtion were not observed in another case-control study (Amin et al., 2008).

Cohort Studies-The results from cohort studies examining the association between intakes of fruit and vegetables and the risk of advanced prostate cancer were largely inconsistent (Table 4). In a cohort study, fruit intake was inversely associated with the risk of advanced prostate cancer [RR (95\%): $0.63(0.43,0.93)$, for $>5$ vs. $\leq$ serving/day]. However, this inverse association was primarily accounted for by fructose intake [RR (95\%) CI: $0.51(0.33,0.80)$, for $>70 \mathrm{~g}$ vs. $\leq 40 \mathrm{~g} / \mathrm{day}$, p-trend $=0.007$ ) (Giovannucci et al., 1998).Takachi et al did not find any association of fruit intake with the risk of advanced prostate cancer (Takachi et al., 2010). Most cohort studies did not reveal that intakes of total vegetables, green leafy vegetables, yellow vegetables, cruciferous vegetables, and fruits protected against advanced prostate cancer (Agalliu et al., 2011; Giovannucci et al., 2003; Takachi et al., 2010).

Micronutrinets abound in fresh vegetables and fruits. Several studies have examined the association between micronutrients and advanced prostate cancer. It was reported that higher intakes of menaquinones (vitamin K2) (Nimptsch et al., 2008), a-tocopherol (Weinstein et al., 2007), $\gamma$-tocopherol, and $\delta$-tocopherol (Wright et al., 2007) were associated with a lower 
risk of advanced prostate cancer. Similar protective effect for advanced disease was observed for high plasma concentrations of total carotenoids (including a-carotene, $\beta$ carotene, $\beta$-cryptoxanthin, canthaxanthin, lutein, lycopene, and zexanthin) in the European Prospective Investigation into Cancer and Nutrition Study (Key et al., 2007). However, null results were obtained for vitamin $\mathrm{C}, \beta$-carotene, $\beta$-cryptoxanthin, lutein/zexanthin, selenium, phylloquinone (vitamin K1), and folate in some other studies (Agalliu et al., 2011; Nimptsch et al., 2008; Stevens et al., 2006; Weinstein et al., 2007). The influence of vitamin supplement use on prostate cancer has been also evaluated (Lawson et al., 2007). In the NIH-AARP Diet and Health Study, men who reported an excessive use of multivitamins experienced a significantly increased risk of advanced prostate cancer [RR (95\%): 1.32 $(1.04,1.67)$, for quartile 4 vs. quartile 1] (Lawson et al., 2007). However, some individual micronutrients (vitamin E, selenium, and folate] were not associated with the risk of advanced prostate cancer in the same study (Lawson et al., 2007). Similar null results were found for nutrients involved in one-carbon metabolism (folate, vitamin B2, vitamin B6, vitamin B12, and methionine) in another cohort study (Kasperzyk et al., 2009).

\section{Lycopene and Tomato Products}

There is a growing body of evidence that lycopene has a beneficial effect on prostate cancer (Dahan et al., 2008; Haseen et al., 2009). Lycopene may suppress prostate carcinogenesis through decreasing lipid oxidation, enhancing antioxidant capacities, and inhibiting cell proliferation (Wei and Giovannucci 2012). The association between lycopene intake and advanced prostate cancer has been evaluated in several studies (Table 5). Giovannucci et.al. reported an inverse association between tomato sauce intake and advanced prostate cancer risk (Giovannucci et al., 2002). In an European study, plasma concentrations of lycopene were associated with a $60 \%$ reduced risk of advanced prostate cancer [RR 95\% CI: 0.40 $(0.19,0.88)$ for quintile 5 vs. quintile 1] (Key et al., 2007). It should be pointed out that protective effect on advanced prostate cancer was not detected in some other studies for intake of lycopene (Agalliu et al., 2011; Kirsh et al., 2006), tomatoes and tomato products (Takachi et al., 2010), and other tomato-based food products (pizza, lasagna, and spagghetti) (Kirsh et al., 2006).

\section{Other dietary factors}

Other dietary factors in relation to advanced prostate cancer are briefly summarized below due to the relative scarcity of data available from epidemiologic studies.

Fish-Three cohorts conducted in the Netherlands (Schuurman et al., 1999), USA (Augustsson et al., 2003), and Finland (Wright et al., 2011) showed that fish consumption did not influence the risk of advanced prostate cancer. However, a significantly reduced risk of metastatic prostate cancer associated with fish consumption was observed in a US cohort [RR (95\% C.I): $0.56(0.37,0.86)$, for quartile 4 vs. quartile 1] (Augustsson et al., 2003).

Tea-A number of animal studies have demonstrated that green tea extracts (including polyphenols and catechins) inhibit the growth of prostate tumor (Henning et al., 2011; Siddiqui et al., 2006). This anticarcinogenic effect has been extensively reviewed in a metaanalysis (Zheng et al., 2011). To our knowledge, only one epidemiologic study has 
investigated the effect of tea consumption on prostate cancer risk (Kurahashi et al., 2008). In that cohort study among Japanese men, green tea consumption was associated with a 48\% reduced risk of advanced prostate cancer after adjustment for confounders [RR (95\% CI): $0.52(0.28-0.96)$ for quintile 5 vs. quintile 1] (Kurahashi et al., 2008). In a randomized chemoprevention trial among 60 volunteers with high-grade prostate intraepithelial neoplasia (precursors of prostate cancer), men who received $600 \mathrm{mg} /$ day of green tea catechins experienced a significant lower risk of prostate cancer than those who received placebo after one-year follow-up (incidence: $3.3 \%$ in intervention vs. $30 \%$ in placebo, $\mathrm{p}<0.01$ ) (Bettuzzi et al., 2006).

Zinc-In a case-control study reported by Gallus et.al, zinc intake was not associated with an altered risk of advanced prostate cancer (Gallus et al., 2007), but a potentially reduced risk was found in a cohort study [RR $(95 \% \mathrm{CI})$ : $0.67(0.41,1.10)$, for quartile 4 vs. quartile 1] (Epstein et al., 2011). This insignificant benefit was also observed for intake of zinc from supplements for both aggressive prostate cancer [RR (95\% CI): $0.70(0.41,1.19)$, for quartile 4 vs. quartile 1)] and metastasized cancer [RR (95\% CI): $0.34(0.13,1.09)$, for quartile 4 vs. quartile 1] (Gonzalez et al., 2009).

Dietary Patterns-In addition to the evaluation of individual nutrients and specific foods, a few case-control studies have investigated whether dietary patterns play a role in the etiology of prostate cancer. The Western diet, characterized by high intake of energy, red meats, and fat and low intake of fiber, has been associated with an increased risk of advanced prostate cancer in an Australian study [OR (95\% CI): $2.11(1.25,3.60)$, for quartile 4 vs. quartile 1 , p-trend $=<0.01$ ] (Ambrosini et al., 2008) and an Uruguayan study [OR (95\% CI): $2.35(1.44,3.85)$, for quartile 4 vs. quartile 1, p-trend $=<0.0001]$ (De Stefani et al., 2010), but not in an American study (Wu et al., 2006).

\section{Discussion}

Epidemiologic evidence overall suggests that the habitual consumption of a diet high in saturated fat, well-done meats, and calcium conferred an increased risk of advanced prostate cancer. The effects of other nutrients and foods on the development of advanced prostate cancer were largely inconsistent across epidemiologic studies.

A number of epidemiologic studies have shown that intakes of total meats and white meats are not associated with the risk of advanced prostate cancer (Alexander et al., 2010). However, methods for cooking meats should be considered when meat consumption is evaluated for its effect on prostate carcinogenesis. Most, although not all, epidemiologic studies have consistently revealed that intakes of well-done meats and mutagens derived from meats cooked at high temperature (e.g. grilled, fried, and barbecued meats) were associated with a significantly elevated risk of advanced prostate cancer in a dose-response manner (p-trend $\$ 0.01$ for well-done meats for most studies) (Koutros et al., 2008; Punnen et al., 2011; Sinha et al., 2009). The ORs or RRs for the highest vs. lowest categories of intake of well-done meats ranged from 1.28 to 2.16 (Cross et al., 2005; Joshi et al., 2012; Koutros et al., 2008; Punnen et al., 2011; Sinha et al., 2009). The potential role of well-done meats in prostate cancer etiology is biologically plausible because prostate tumors have been 
induced in rats fed on a meat-derived mutagen (PHiP) (Shirai et al., 1997). Furthermore, PhIP-DNA adducts that may cause DNA mutations and initiate carcinogenesis were detected in all lobes of the prostate of rats receiving PhIP in the same study (Shirai et al., 1997).

As mentioned previously, ecologic and migrant studies strongly suggest that intake of fat and especially animal fat (primarily saturated fat) was associated with an increased risk of prostate cancer (Rose et al., 1986; Whittemore et al., 1995). This obsevation has gained further support from increasing trends in prostate cancer incidence in East Asia over last few decades probably as a consequence of nutrition transition toward the Western diet (Zhang et al., 2012). However, the results from analytical epidemiologic studies on the effect of fat and types of fat on prostate cancer risk were mixed. Most case-control studies have shown a significant, positive association between intakes of total fat and especially saturated fat and the risk of advanced prostate cancer, with risk estimates (ORs) ranged from 1.4 to 8.7 (Bairati et al., 1998; De Stefani et al., 2000; Whittemore et al., 1995). A number of animal studies suggest that fat is implicated in prostate carcinogenesis by promoting oxidative stress and inflammation in the prostate gland (Hill, 1987; Vykhovanets et al., 2011).

To date, one case-control study has demonstrated that dietary intake of calcium was monotonically associated with an increased risk of advanced prostate cancer (p-trend = 0.001) (Rowland et al., 2011). Similar but less consistent results were obtained from cohort studies. Vitamin D was not associated with an elevated risk of advanced prostate cancer (Giovannucci and Clinton, 1998). Vitamin D enhances the absorption of calcium in the gut. Experimental studies have demonstrated that vitamin D promotes the differentiation and suppresses the proliferation of prostate cells (Samuel and Sitrin, 2008). It has been put forward that high calcium intake increases the risk of prostate cancer through reducing circulating levels of 1,25-dihydroxyvitamin D, most active form of this vitamin (Williams et al., 2012).

Most case-control studies have demonstrated a significant, inverse association between intakes of vegetables (yellow-green, cruciferous, carrots, and legumes) and the risk of advanced prostate cancer, with risk estimates (ORs) ranged from 0.36 to 0.96 (Hardin et al., 2011; Kolonel et al., 2000). However, no association was found between intake of vegetables and the risk of advanced prostate cancer in most cohort studies (Agalliu et al., 2011; Stevens et al., 2006; Takachi et al., 2010). Similarly, fruit intake was overall not associated with the risk of advanced prostate cancer in both case-control (Amin et al., 2008; Hardin et al., 2011; Kolonel et al., 2000) and cohort studies (Takachi et al., 2010). Excessive use of multivitamins increases the risk of advanced prostate cancer (Lawson et al., 2007). Vitamin E naturally occurs in eight chemical forms that include tocopherols and tocotrienols (Jiang et al., 2001); $a-, \gamma-$, and $\delta$-tocopherol intake has been significantly associated with a reduced risk of advanced prostate cancer, with reported risk estimates (RRs) being from 0.36 to 0.96 (Weinstein et al., 2007; Wright et al., 2007). Vegetables and fruits contain a variety of chemical compounds including vitamin $\mathrm{C}$, carotenoids, flavonoids, phenols, and fiber. These molecules possess antioxidant properties, bind and dilute carcinogens, or alter hormone metabolism (McDermott, 2000), which offers biochemical mechanisms for the protective effect of vegetables and fruits on prostate cancer. 
Lycopene is derived largely from tomatoes and tomato-based products (Dahan et al., 2008). As experimental studies have provided ample evidence supporting that lycopene has anticarcinogenic properties that have been mentioned previously, a number of epidemiologic studies have investigated its effect on total prostate cancer (Etminan et al., 2004). A metaanalysis showed a modest inverse association between lycopene intake and the risk of total prostate cancer (Etminan et al., 2004). Among a few studies that reported risk estimates for advanced prostate cancer, a significantly reduced risk was observed for men who exhibited high plasma concentrations of lycopene in an European cohort study (Key et al., 2007). However, this protective effect was not detected in other cohort studies based on the analysis of dietary intake of lycopene (Agalliu et al., 2011; Kirsh et al., 2006). It has been reported that lycopene from raw and cooked tomatoes have different intestinal bioavailability (Gartner et al., 1997), which may offer a partial explanation for the null effect of dietary lycopene on advanced prostate cancer.

The results obtained from epidemiologic studies of dietary patterns in relation to disease risk are more directly applicable to dietary recommendations than those from studies of individual nutrients because people can manipulate nutrient intake by their choice of foods. Two case-control studies have shown that maintaining a Western diet pattern was significantly associated with an over two-fold elevated risk of advanced prostate cancer in a dose-response manner (p-trend < 0.001) (Ambrosini et al., 2008; De Stefani et al., 2010). Similar results were not observed from a cohort study (Wu et al., 2006). In addition, other dietary patterns (e.g. a prudent dietary pattern) were not found to influence the risk of advanced prostate cancer (De Stefani et al., 2010; Wu et al., 2006). Collectively, more epidemiologic studies are encouraged to evaluate the effect of various dietary patterns on the occurrence of total and particularly aggressive prostate cancer because of the importance and relevance of research in this area for cancer etiology, prevention, and control.

Several factors might have contributed to observed inconsistent results of some nutrients and foods in relation to advanced prostate cancer. To date, most studies on this topic have examined total prostate cancer only. In the studies that reported separate results for advanced tumors, the number of advanced prostate cases was generally small, which offer inadequate statistical power to detect modest effects. In addition, scarce data are available on the effect of diet on the risk of aggressive and metastatic prostate cancer. Measured and unmeasured confounding should be considered in the interpretation of results obtained from any epidemiologic studies. Although age, race, and family history were treated as confounders in most studies, adjustment for other potential confounding factors were different among reviewed studies. Last, food frequency questionnaire has been used in the majority of nutritional epidemiologic studies over last two decades. A number of validation studies have shown that underreporting of fat and meats and over reporting of vegetables and fruits intake are common among these studies (Macdiarmid and Blundell, 1998). These dietary measurement errors could result in misclassification of subjects with regard to their dietary intakes of nutrients and foods and consequently the attenuation of true associations of dietary factors with the risk of advanced prostate cancer (Bingham et al., 2003). Recall bias inherent in food frequency questionnaire could be overcome by measuring biochemical indicators of nutrients in various biological specimens (e.g. blood, urine, and tissue). However, these nutritional biomarkers were not determined in most epidemiologic studies. 
In summary, epidemiologic studies conducted to date overall suggest that high intakes of saturated fat, meats cooked at high temperature, and calcium are associated with an increased risk of advanced prostate cancer. It should be noted that these results were largely based on a relatively small number of advanced prostate tumors in most epidemiologic studies reviewed. More adequately-powered epidemiologic studies (especially prospective cohort studies) that measure both dietary intake of nutrients and their biomarkers are warranted to further elucidate the role of diet in the etiology of advanced prostate cancer. As dietary factors are modifiable, identifying nutrients or food groups that modulate the risk of advanced prostate cancer can offer effective and practical strategies for its primary prevention.

\section{References}

Agalliu I, Kirsh VA, Kreiger N, Soskolne CL, Rohan TE. Oxidative balance score and risk of prostate cancer: results from a case-cohort study. Cancer Epidemiol. 2011; 35:353-361. [PubMed: 21145797]

Ahn J, Albanes D, Peters U, Schatzkin A, Lim U, Freedman M, et al. Dairy products, calcium intake, and risk of prostate cancer in the prostate, lung, colorectal, and ovarian cancer screening trial. Cancer Epidemiol Biomarkers Prev. 2007; 16:2623-2630. [PubMed: 18086766]

Alexander DD, Mink PJ, Cushing CA, Sceurman B. A review and meta-analysis of prospective studies of red and processed meat intake and prostate cancer. Nutr J. 2010; 9:50. [PubMed: 21044319]

Allen NE, Key TJ, Appleby PN, Travis RC, Roddam AW, Tjonneland A, et al. Animal foods, protein, calcium and prostate cancer risk: the European Prospective Investigation into Cancer and Nutrition. Br J Cancer. 2008; 98:1574-1581. [PubMed: 18382426]

Ambrosini GL, Fritschi L, de Klerk NH, Mackerras D, Leavy J. Dietary patterns identified using factor analysis and prostate cancer risk: a case control study in Western Australia. Ann Epidemiol. 2008; 18:364-370. [PubMed: 18261927]

Amin M, Jeyaganth S, Fahmy N, Begin LR, Aronson S, Jacobson S, et al. Dietary habits and prostate cancer detection: a case-control study. Can Urol Assoc J. 2008; 2:510-515. [PubMed: 18953447]

Augustsson K, Michaud DS, Rimm EB, Leitzmann MF, Stampfer MJ, Willett WC, et al. A prospective study of intake of fish and marine fatty acids and prostate cancer. Cancer Epidemiol Biomarkers Prev. 2003; 12:64-67. [PubMed: 12540506]

Bairati I, Meyer F, Fradet Y, Moore L. Dietary fat and advanced prostate cancer. J Urol. 1998; 159:1271-1275. [PubMed: 9507851]

Bettuzzi SM, Brausi F, Rizzi G, Castagnetti G, Peracchia G, Corti A. Chemoprevention of human prostate cancer by oral administration of green tea catechins in volunteers with high-grade prostate intraepithelial neoplasia: a preliminary report from a one-year proof-of-principle study. Cancer Res. 2006; 66:1234-40. [PubMed: 16424063]

Bingham SA, Luben R, Welch A, Wareham N, Khaw KT, Day N. Are imprecise methods obscuring a relation between fat and breast cancer? Lancet. 2003; 362:212-214. [PubMed: 12885485]

Brassell SA, Rice KR, Parker PM, Chen Y, Farrell JS, Cullen J, et al. Prostate cancer in men 70 years old or older, indolent or aggressive: clinicopathological analysis and outcomes. J Urol. 2011; 185:132-137. [PubMed: 21074211]

Choi JY, Neuhouser ML, Barnett MJ, Hong CC, Kristal AR, Thornquist MD, et al. Iron intake, oxidative stress-related genes (MnSOD and MPO) and prostate cancer risk in CARET cohort. Carcinogenesis. 2008; 29:964-970. [PubMed: 18296681]

Cross AJ, Peters U, Kirsh VA, Andriole GL, Reding D, Hayes RB, et al. A prospective study of meat and meat mutagens and prostate cancer risk. Cancer Res. 2005; 65:11779-11784. [PubMed: 16357191]

Dahan K, Fennal M, Kumar NB. Lycopene in the prevention of prostate cancer. J Soc Integr Oncol. 2008; 6:29-36. [PubMed: 18302908] 
De Stefani E, Deneo-Pellegrini H, Boffetta P, Ronco A, Mendilaharsu M. Alpha-linolenic acid and risk of prostate cancer: a case-control study in Uruguay. Cancer Epidemiol Biomarkers Prev. 2000; 9:335-338. [PubMed: 10750674]

De Stefani E, Ronco AL, Deneo-Pellegrini H, Boffetta P, Aune D, Acosta G, et al. Dietary patterns and risk of advanced prostate cancer: a principal component analysis in Uruguay. Cancer Causes Control. 2010; 21:1009-1016. [PubMed: 20198507]

Epstein MM, Kasperzyk JL, Andren O, Giovannucci EL, Wolk A, Hakansson N, et al. Dietary zinc and prostate cancer survival in a Swedish cohort. Am J Clin Nutr. 2011; 93:586-593. [PubMed: 21228268]

Etminan M, Takkouche B, Caamano-Isorna F. The role of tomato products and lycopene in the prevention of prostate cancer: a meta-analysis of observational studies. Cancer Epidemiol Biomarkers Prev. 2004; 13:340-345. [PubMed: 15006906]

Gallus S, Foschi R, Negri E, Talamini R, Franceschi S, Montella M, et al. Dietary zinc and prostate cancer risk: a case-control study from Italy. Eur Urol. 2007; 52:1052-1056. [PubMed: 17292532]

Gartner C, Stahl W, Sies H. Lycopene is more bioavailable from tomato paste than from fresh tomatoes. Am J Clin Nutr. 1997; 66:116-122. [PubMed: 9209178]

Giovannucci E. Tomatoes, tomato-based products, lycopene, and cancer: review of the epidemiologic literature. J Natl Cancer Inst. 1999; 91:317-331. [PubMed: 10050865]

Giovannucci E, Clinton SK. Tomatoes, lycopene, and prostate cancer. Proc Soc Exp Biol Med. 1998; 218:129-139. [PubMed: 9605211]

Giovannucci E, Rimm EB, Liu Y, Stampfer MJ, Willett WC. A prospective study of tomato products, lycopene, and prostate cancer risk. J Natl Cancer Inst. 2002; 94:391-398. [PubMed: 11880478]

Giovannucci E, Rimm EB, Liu Y, Stampfer MJ, Willett WC. A prospective study of cruciferous vegetables and prostate cancer. Cancer Epidemiol Biomarkers Prev. 2003; 12:1403-1409. [PubMed: 14693729]

Giovannucci E, Rimm EB, Wolk A, Ascherio A, Stampfer MJ, Colditz GA, et al. Calcium and fructose intake in relation to risk of prostate cancer. Cancer Res. 1998; 58:442-447. [PubMed: 9458087]

Gonzalez A, Peters U, Lampe JW, White E. Zinc intake from supplements and diet and prostate cancer. Nutr Cancer. 2009; 61:206-215. [PubMed: 19235036]

Gu D, McNaughton L, Lemaster D, Lake BG, Gooderham NJ, Kadlubar FF, et al. A comprehensive approach to the profiling of the cooked meat carcinogens 2-amino-3,8-dimethylimidazo[4,5f] quinoxaline, 2-amino-1-methyl-6-phenylimidazo[4,5-b]pyridine, and their metabolites in human urine. Chem Res Toxicol. 2010; 23:788-801. [PubMed: 20192249]

Hardin J, Cheng I, Witte JS. Impact of consumption of vegetable, fruit, grain, and high glycemic index foods on aggressive prostate cancer risk. Nutr Cancer. 2011; 63:860-872. [PubMed: 21774611]

Haseen F, Cantwell MM, O'Sullivan JM, Murray LJ. Is there a benefit from lycopene supplementation in men with prostate cancer? A systematic review. Prostate Cancer Prostatic Dis. 2009; 12:325332. [PubMed: 19901932]

Hayes RB, Ziegler RG, Gridley G, Swanson C, Greenberg RS, Swanson GM, et al. Dietary factors and risks for prostate cancer among blacks and whites in the United States. Cancer Epidemiol Biomarkers Prev. 1999; 8:25-34. [PubMed: 9950236]

Henning SM, Wang P, Heber D. Chemopreventive effects of tea in prostate cancer: green tea versus black tea. Mol Nutr Food Res. 2011; 55:905-20. [PubMed: 21538852]

Hill MJ. Dietary fat and human cancer (review). Anticancer Res. 1987; 7:281-292. [PubMed: 3296942]

Hsing AW, Devesa SS. Trends and patterns of prostate cancer: what do they suggest? Epidemiol Rev. 2001; 23:3-13. [PubMed: 11588851]

Jemal A, Bray F, Center MM, Ferlay J, Ward E, Forman D. Global cancer statistics. CA Cancer J Clin. 2011; 61:69-90. [PubMed: 21296855]

Jiang Q, Christen S, Shigenaga MK, Ames BN. gamma-tocopherol, the major form of vitamin E in the US diet, deserves more attention. Am J Clin Nutr. 2001; 74:714-722. [PubMed: 11722951]

John EM, Stern MC, Sinha R, Koo J. Meat consumption, cooking practices, meat mutagens, and risk of prostate cancer. Nutr Cancer. 2011; 63:525-537. [PubMed: 21526454] 
Joshi AD, Corral R, Catsburg C, Lewinger JP, Koo J, John EM, Stern MC. Red meat and poultry, cooking practices, genetic susceptibility and risk of prostate cancer: results from a multiethnic case-control study. Carcinogenesis. 2012; 33:2108-2118. [PubMed: 22822096]

Kasperzyk JL, Fall K, Mucci LA, Hakansson N, Wolk A, Johansson JE, et al. One-carbon metabolismrelated nutrients and prostate cancer survival. Am J Clin Nutr. 2009; 90:561-569. [PubMed: 19571228]

Key TJ. Fruit and vegetables and cancer risk. Br J Cancer. 2011; 104:6-11. [PubMed: 21119663]

Key TJ, Appleby PN, Allen NE, Travis RC, Roddam AW, Jenab M, et al. Plasma carotenoids, retinol, and tocopherols and the risk of prostate cancer in the European Prospective Investigation into Cancer and Nutrition study. Am J Clin Nutr. 2007; 86:672-681. [PubMed: 17823432]

Kirsh VA, Mayne ST, Peters U, Chatterjee N, Leitzmann MF, Dixon LB, et al. A prospective study of lycopene and tomato product intake and risk of prostate cancer. Cancer Epidemiol Biomarkers Prev. 2006; 15:92-98. [PubMed: 16434593]

Kolonel LN, Hankin JH, Whittemore AS, Wu AH, Gallagher RP, Wilkens LR, et al. Vegetables, fruits, legumes and prostate cancer: a multiethnic case-control study. Cancer Epidemiol Biomarkers Prev. 2000; 9:795-804. [PubMed: 10952096]

Koutros S, Cross AJ, Sandler DP, Hoppin JA, Ma X, Zheng T, et al. Meat and meat mutagens and risk of prostate cancer in the Agricultural Health Study. Cancer Epidemiol Biomarkers Prev. 2008; 17:80-87. [PubMed: 18199713]

Kurahashi NS, Sasazuki S, Iwasaki M, Inoue M, Tsugane S. JPHC Study Group. Green tea consumption and prostate cancer risk in Japanese men: a prospective study. Am J Epidemiol. 2008; 167:71-7. [PubMed: 17906295]

Lawson KA, Wright ME, Subar A, Mouw T, Hollenbeck A, Schatzkin A, et al. Multivitamin use and risk of prostate cancer in the National Institutes of Health-AARP Diet and Health Study. J Natl Cancer Inst. 2007; 99:754-764. [PubMed: 17505071]

Leitzmann MF, Rohrmann S. Risk factors for the onset of prostatic cancer: age, location, and behavioral correlates. Clin Epidemiol. 2012; 4:1-11. [PubMed: 22291478]

Ma RW, Chapman K. A systematic review of the effect of diet in prostate cancer prevention and treatment. J Hum Nutr Diet. 2009; 22:187-199. [PubMed: 19344379]

Macdiarmid J, Blundell J. Assessing dietary intake: Who, what and why of under-reporting. Nutr Res Rev. 1998; 11:231-253. [PubMed: 19094249]

McDermott JH. Antioxidant nutrients: current dietary recommendations and research update. J Am Pharm Assoc (Wash). 2000; 40:785-799. [PubMed: 11111359]

Michaud DS, Augustsson K, Rimm EB, Stampfer MJ, Willet WC, Giovannucci E. A prospective study on intake of animal products and risk of prostate cancer. Cancer Causes Control. 2001; 12:557567. [PubMed: 11519764]

Nimptsch K, Rohrmann S, Linseisen J. Dietary intake of vitamin K and risk of prostate cancer in the Heidelberg cohort of the European Prospective Investigation into Cancer and Nutrition (EPICHeidelberg). Am J Clin Nutr. 2008; 87:985-992. [PubMed: 18400723]

Park Y, Mitrou PN, Kipnis V, Hollenbeck A, Schatzkin A, Leitzmann MF. Calcium, dairy foods, and risk of incident and fatal prostate cancer: the NIH-AARP Diet and Health Study. Am J Epidemiol. 2007; 166:1270-1279. [PubMed: 18000020]

Punnen S, Hardin J, Cheng I, Klein EA, Witte JS. Impact of meat consumption, preparation, and mutagens on aggressive prostate cancer. PLoS One. 2011; 6:e27711. [PubMed: 22132129]

Richman EL, Kenfield SA, Stampfer MJ, Giovannucci EL, Chan JM. Egg, red meat, and poultry intake and risk of lethal prostate cancer in the prostate-specific antigen-era: incidence and survival. Cancer Prev Res (Phila). 2011; 4:2110-2121. [PubMed: 21930800]

Rose DP. Dietary fatty acids and cancer. Am J Clin Nutr. 1997; 66:998S-1003S. [PubMed: 9322580]

Rose DP, Boyar AP, Wynder EL. International comparisons of mortality rates for cancer of the breast, ovary, prostate, and colon, and per capita food consumption. Cancer. 1986; 58:2363-2371. [PubMed: 3768832]

Rowland GW, Schwartz GG, John EM, Ingles SA. Calcium intake and prostate cancer among African Americans: Effect modification by vitamin D receptor calcium absorption genotype. J Bone Miner Res. 2011 
Samuel S, Sitrin MD. Vitamin D's role in cell proliferation and differentiation. Nutr Rev. 2008; 66:S116-124. [PubMed: 18844838]

Sander A, Linseisen J, Rohrmann S. Intake of heterocyclic aromatic amines and the risk of prostate cancer in the EPIC-Heidelberg cohort. Cancer Causes Control. 2011; 22:109-114. [PubMed: 21103922]

Schuurman AG, van den Brandt PA, Dorant E, Goldbohm RA. Animal products, calcium and protein and prostate cancer risk in The Netherlands Cohort Study. Br J Cancer. 1999; 80:1107-1113. [PubMed: 10362125]

Shirai T, Sano M, Tamano S, Takahashi S, Hirose M, Futakuchi M, et al. The prostate: a target for carcinogenicity of 2-amino-1-methyl-6-phenylimidazo[4,5-b]pyridine (PhIP) derived from cooked foods. Cancer Res. 1997; 57:195-198. [PubMed: 9000552]

Siddiqui IA, Adhami VM, Saleem M, Mukhtar H. Beneficial effects of tea and its polyphenols against prostate cancer. Mol Nutr Food Res. 2006; 50:130-43. [PubMed: 16425281]

Sinha R, Park Y, Graubard BI, Leitzmann MF, Hollenbeck A, Schatzkin A, et al. Meat and meatrelated compounds and risk of prostate cancer in a large prospective cohort study in the United States. Am J Epidemiol. 2009; 170:1165-1177. [PubMed: 19808637]

Sinha R, Rothman N, Salmon CP, Knize MG, Brown ED, Swanson CA, et al. Heterocyclic amine content in beef cooked by different methods to varying degrees of doneness and gravy made from meat drippings. Food Chem Toxicol. 1998; 36:279-287. [PubMed: 9651044]

Slattery ML, Schumacher MC, West DW, Robison LM, French TK. Food-consumption trends between adolescent and adult years and subsequent risk of prostate cancer. Am J Clin Nutr. 1990; 52:752-757. [PubMed: 2403069]

Stevens VL, Rodriguez C, Pavluck AL, McCullough ML, Thun MJ, Calle EE. Folate nutrition and prostate cancer incidence in a large cohort of US men. Am J Epidemiol. 2006; 163:989-996. [PubMed: 16554345]

Sugimura T, Wakabayashi K, Nakagama H, Nagao M. Heterocyclic amines: Mutagens/carcinogens produced during cooking of meat and fish. Cancer Sci. 2004; 95:290-299. [PubMed: 15072585]

Takachi R, Inoue M, Sawada N, Iwasaki M, Sasazuki S, Ishihara J, et al. Fruits and vegetables in relation to prostate cancer in Japanese men: the Japan Public Health Center-Based Prospective Study. Nutr Cancer. 2010; 62:30-39. [PubMed: 20043257]

Tan HL, Thomas-Ahner JM, Grainger EM, Wan L, Francis DM, Schwartz SJ, et al. Tomato-based food products for prostate cancer prevention: what have we learned? Cancer Metastasis Rev. 2010; 29:553-568. [PubMed: 20803054]

Vykhovanets EV, Shankar E, Vykhovanets OV, Shukla S, Gupta S. High-fat diet increases NF-kappaB signaling in the prostate of reporter mice. Prostate. 2011; 71:147-156. [PubMed: 20632379]

Wei MY, Giovannucci EL. Lycopene, Tomato Products, and Prostate Cancer Incidence: A Review and Reassessment in the PSA Screening Era. J Oncol. 2012; 2012:271063. [PubMed: 22690215]

Weinstein SJ, Wright ME, Lawson KA, Snyder K, Mannisto S, Taylor PR, et al. Serum and dietary vitamin E in relation to prostate cancer risk. Cancer Epidemiol Biomarkers Prev. 2007; 16:12531259. [PubMed: 17548693]

Whittemore AS, Kolonel LN, Wu AH, John EM, Gallagher RP, Howe GR, et al. Prostate cancer in relation to diet, physical activity, and body size in blacks, whites, and Asians in the United States and Canada. J Natl Cancer Inst. 1995; 87:652-661. [PubMed: 7752270]

Williams CD, Whitley BM, Hoyo C, Grant DJ, Schwartz GG, Presti JC, et al. Dietary calcium and risk for prostate cancer: a case-control study among US veterans. Prev Chronic Dis. 2012; 9:E39. [PubMed: 22239754]

Wright ME, Bowen P, Virtamo J, Albanes D, Gann PH. Estimated phytanic acid intake and prostate cancer risk: A prospective cohort study. Int J Cancer. 2011

Wright ME, Weinstein SJ, Lawson KA, Albanes D, Subar AF, Dixon LB, et al. Supplemental and dietary vitamin $\mathrm{E}$ intakes and risk of prostate cancer in a large prospective study. Cancer Epidemiol Biomarkers Prev. 2007; 16:1128-1135. [PubMed: 17548674]

Wu K, Hu FB, Willett WC, Giovannucci E. Dietary patterns and risk of prostate cancer in U.S. men. Cancer Epidemiol Biomarkers Prev. 2006; 15:167-171. [PubMed: 16434606] 
Zhang J, Dhakal IB, Zhao Z, Li L. Trends in mortality from cancers of the breast, colon, prostate, esophagus, and stomach in East Asia: role of nutrition transition. Eur J Cancer Prev. 2012; 21:480-489. [PubMed: 22357483]

Zheng J, Yang B, Huang T, Yu Y, Yang J, Li D. Green tea and black tea consumption and prostate cancer risk: an exploratory meta-analysis of observational studies. Nutr Cancer. 2011; 63:663-72. [PubMed: 21667398]

Zhu G, Zhang YQ, Wan B. Role of dietary factors in prostate cancer development. Zhonghua Nan Ke Xue. 2005; 11:375-378. [PubMed: 15934465] 


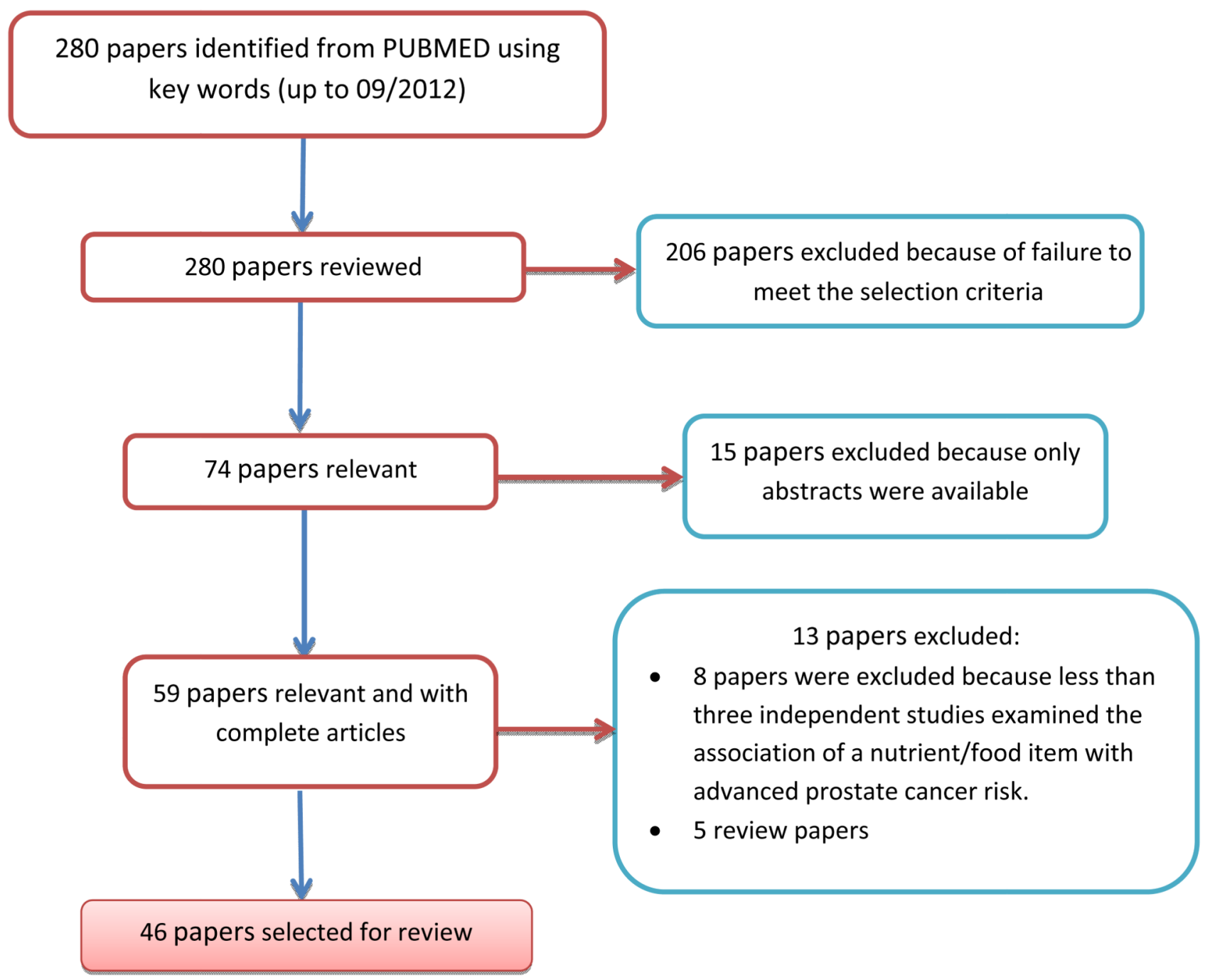

Figure 1. Flowchart of selecting papers included in this review 


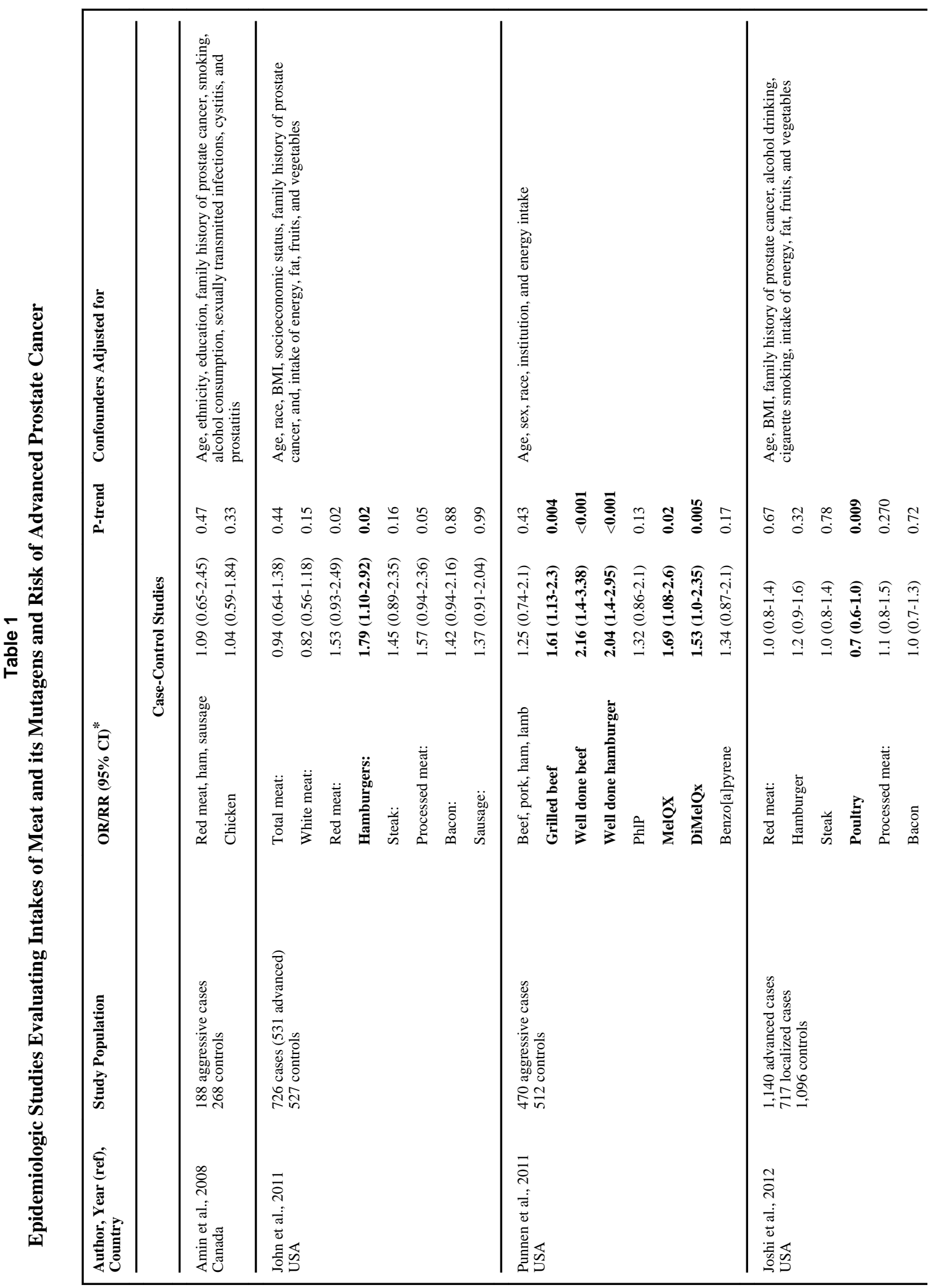

Eur J Cancer Prev. Author manuscript; available in PMC 2015 March 01. 


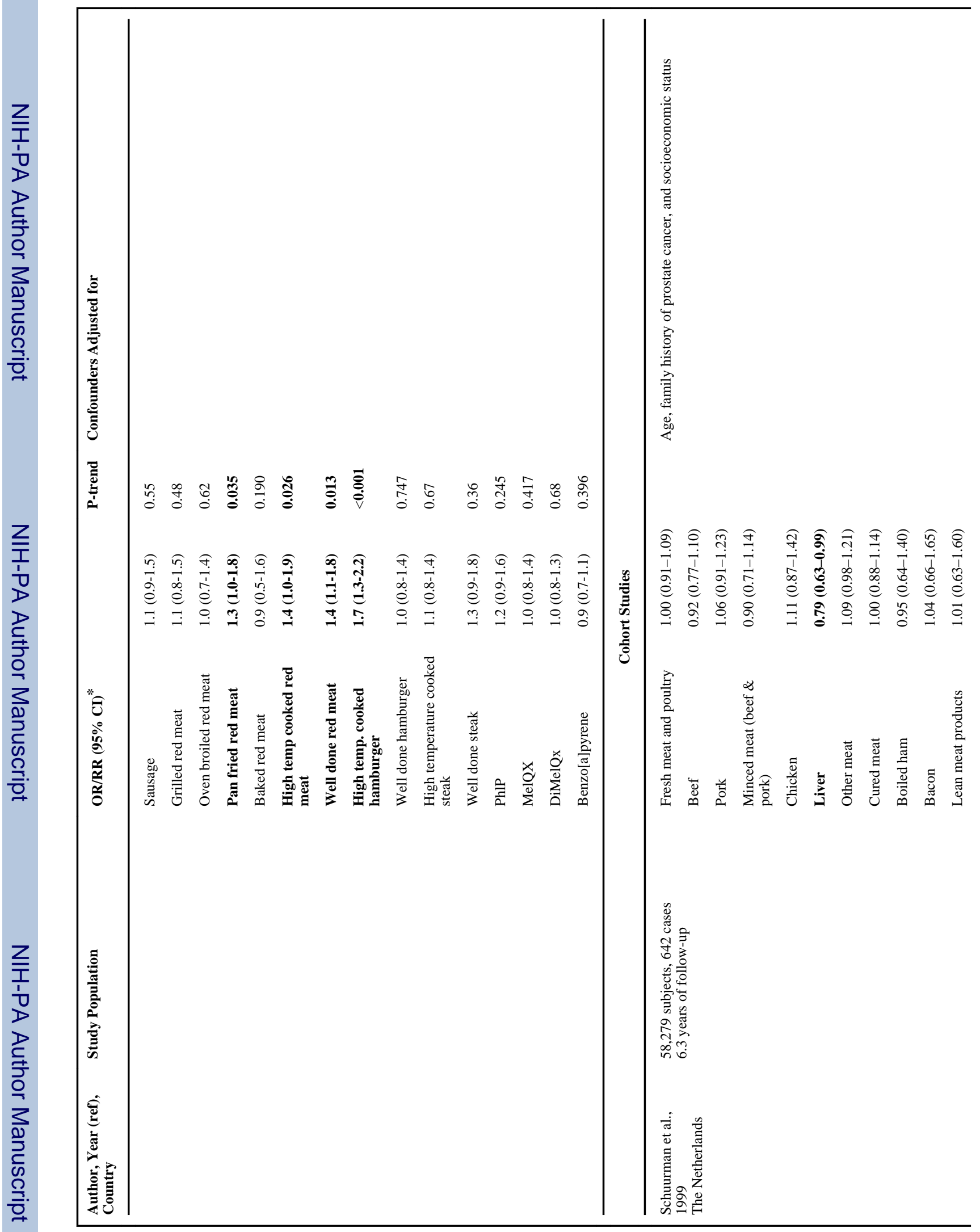

Eur J Cancer Prev. Author manuscript; available in PMC 2015 March 01. 


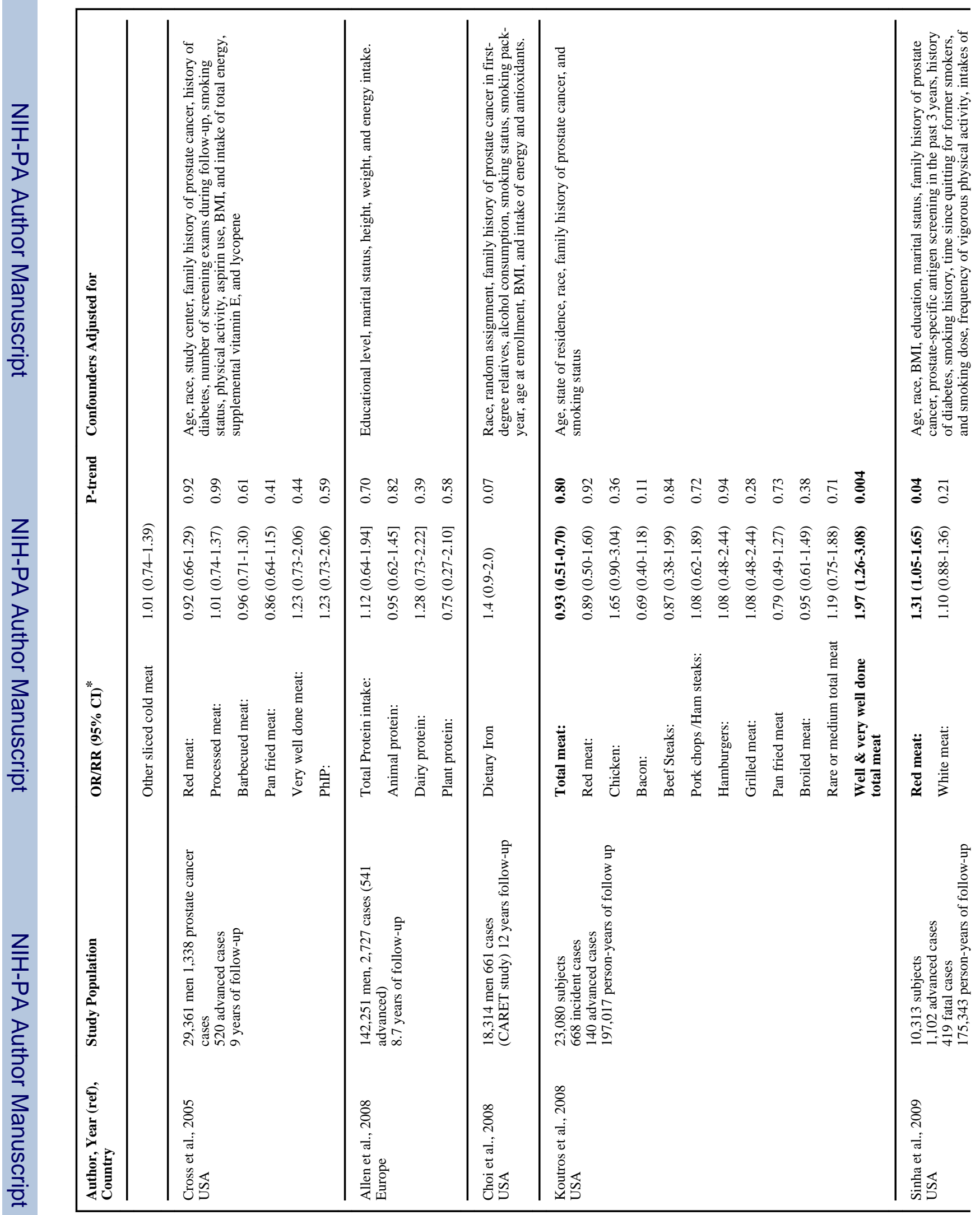

Eur J Cancer Prev. Author manuscript; available in PMC 2015 March 01. 


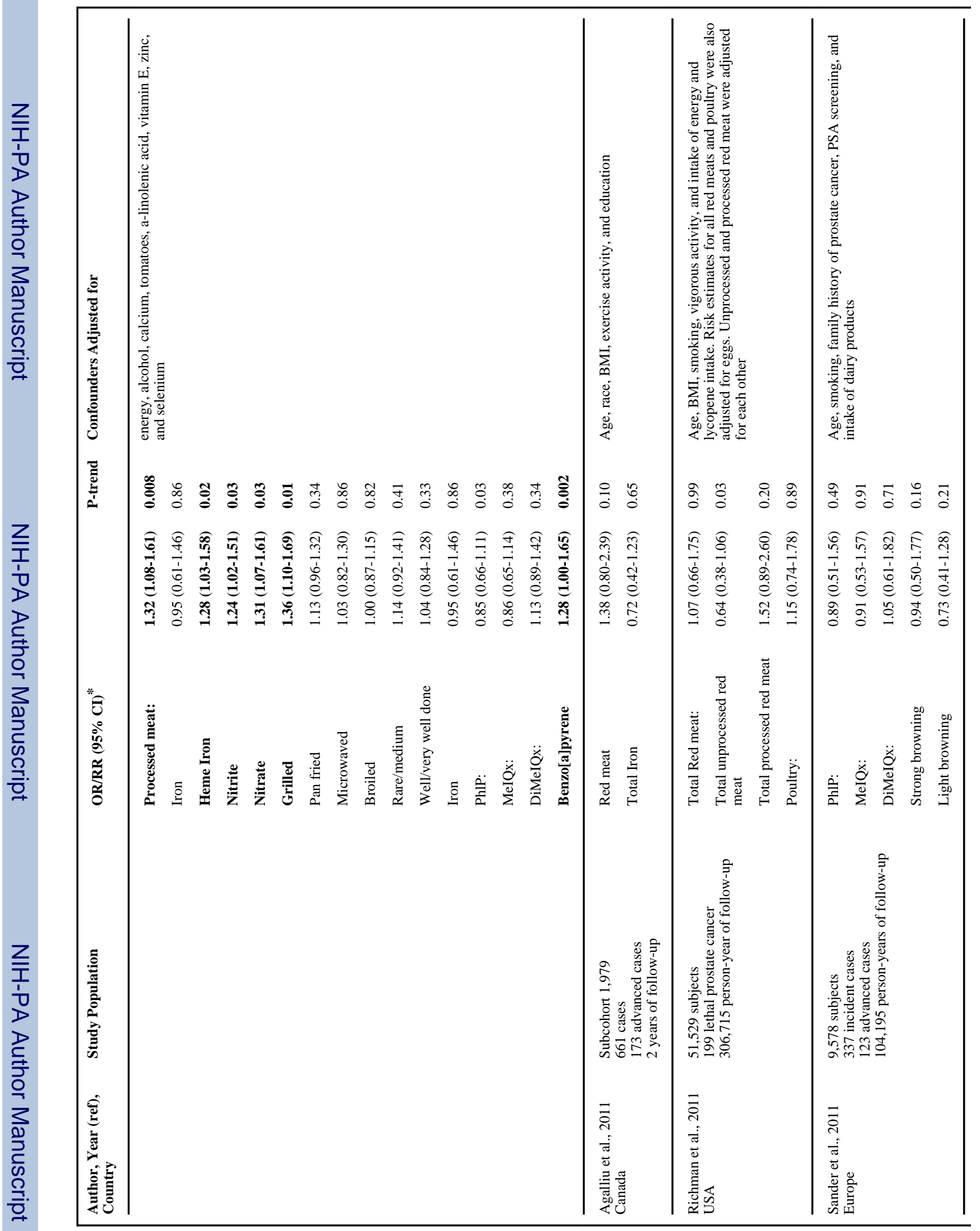

Eur J Cancer Prev. Author manuscript; available in PMC 2015 March 01. 


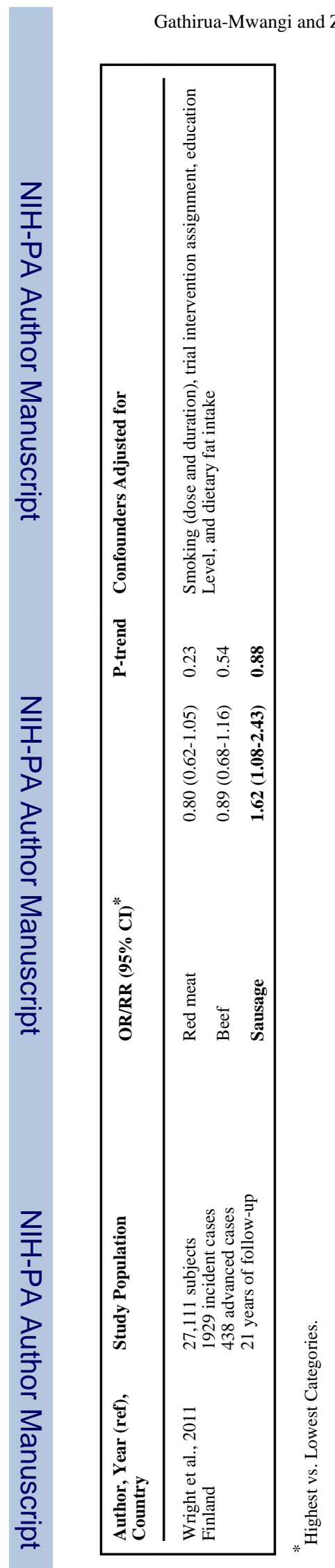

Page 21

Eur J Cancer Prev. Author manuscript; available in PMC 2015 March 01. 


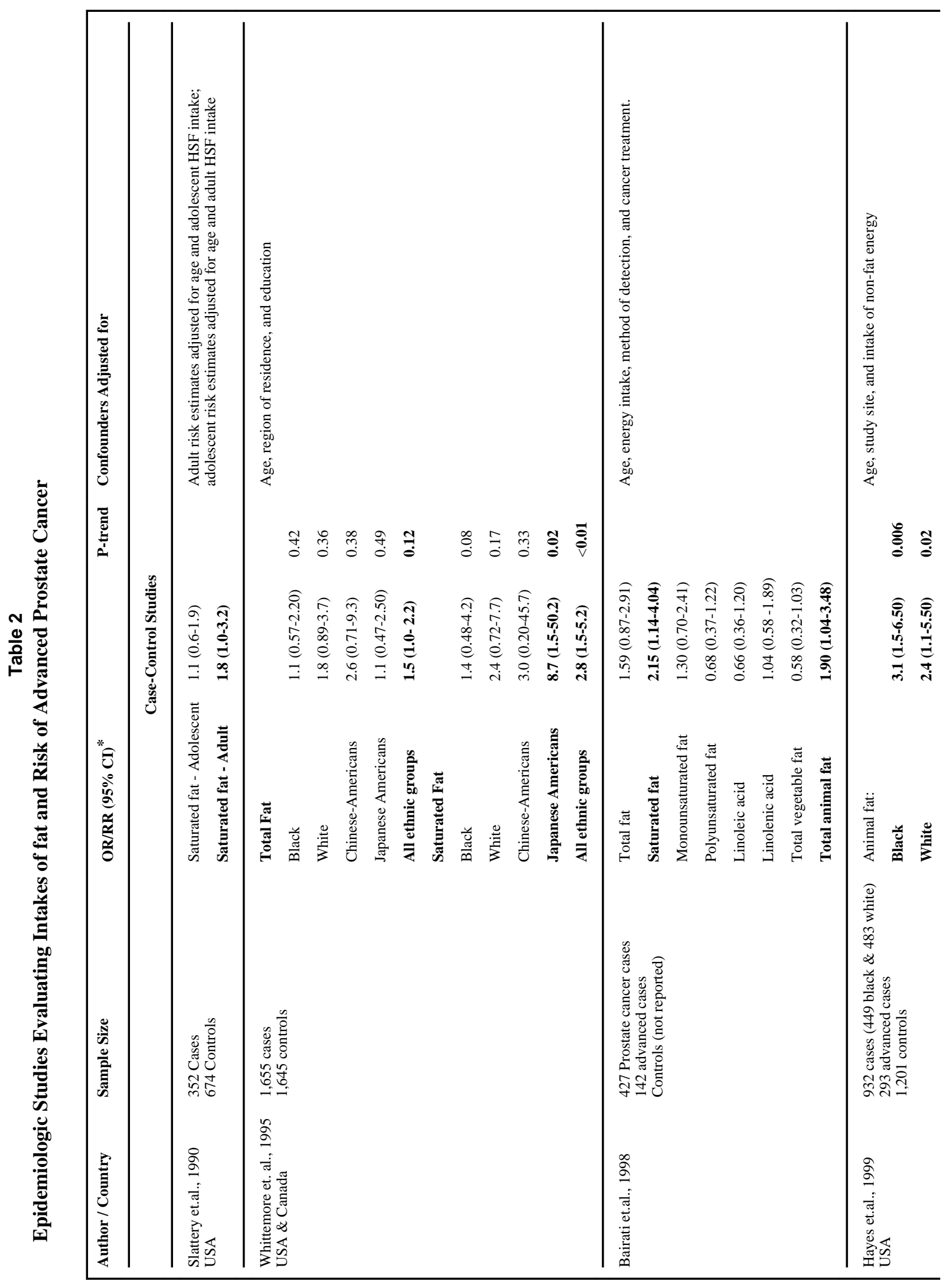

Eur J Cancer Prev. Author manuscript; available in PMC 2015 March 01. 


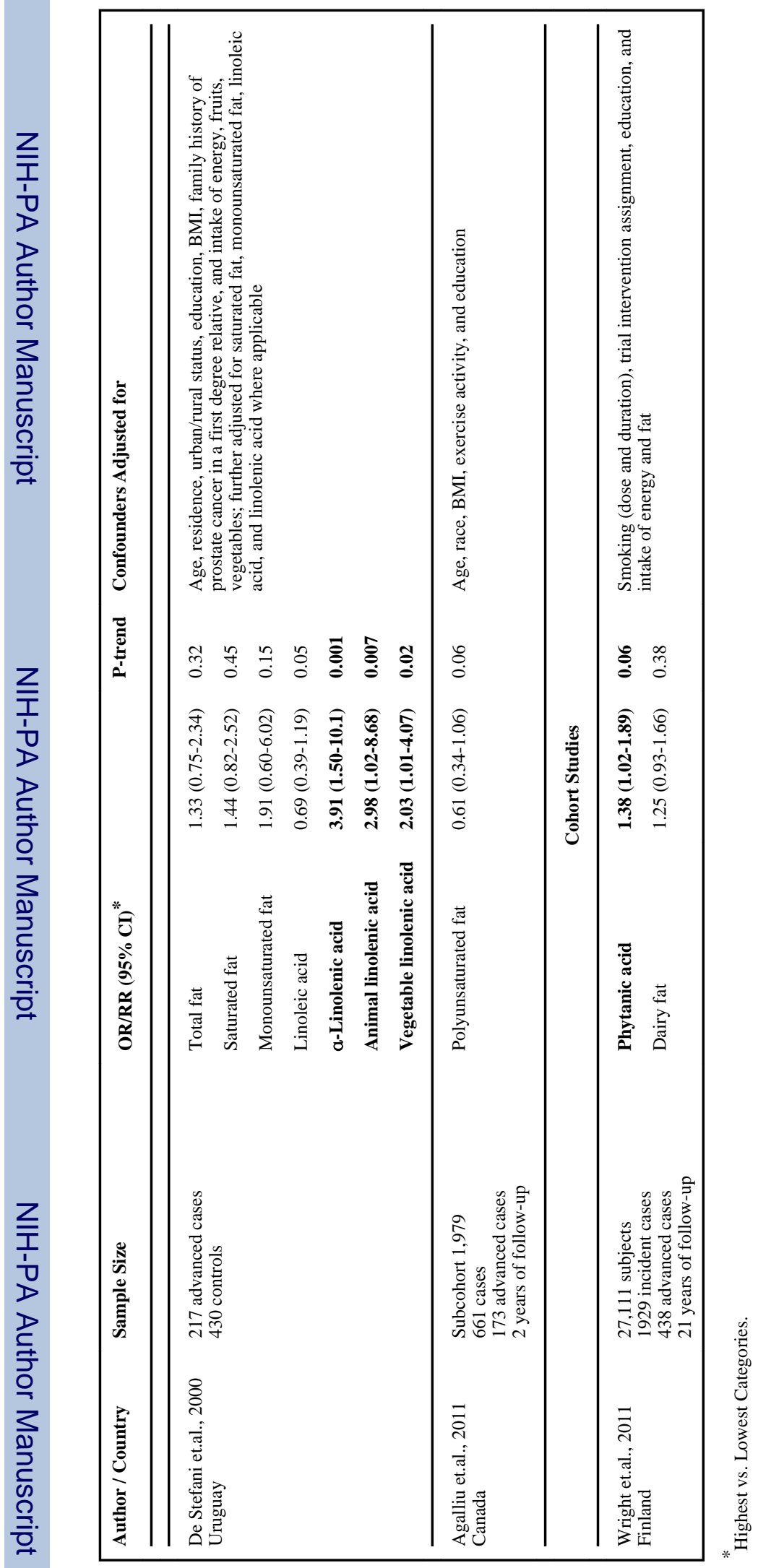

Eur J Cancer Prev. Author manuscript; available in PMC 2015 March 01. 


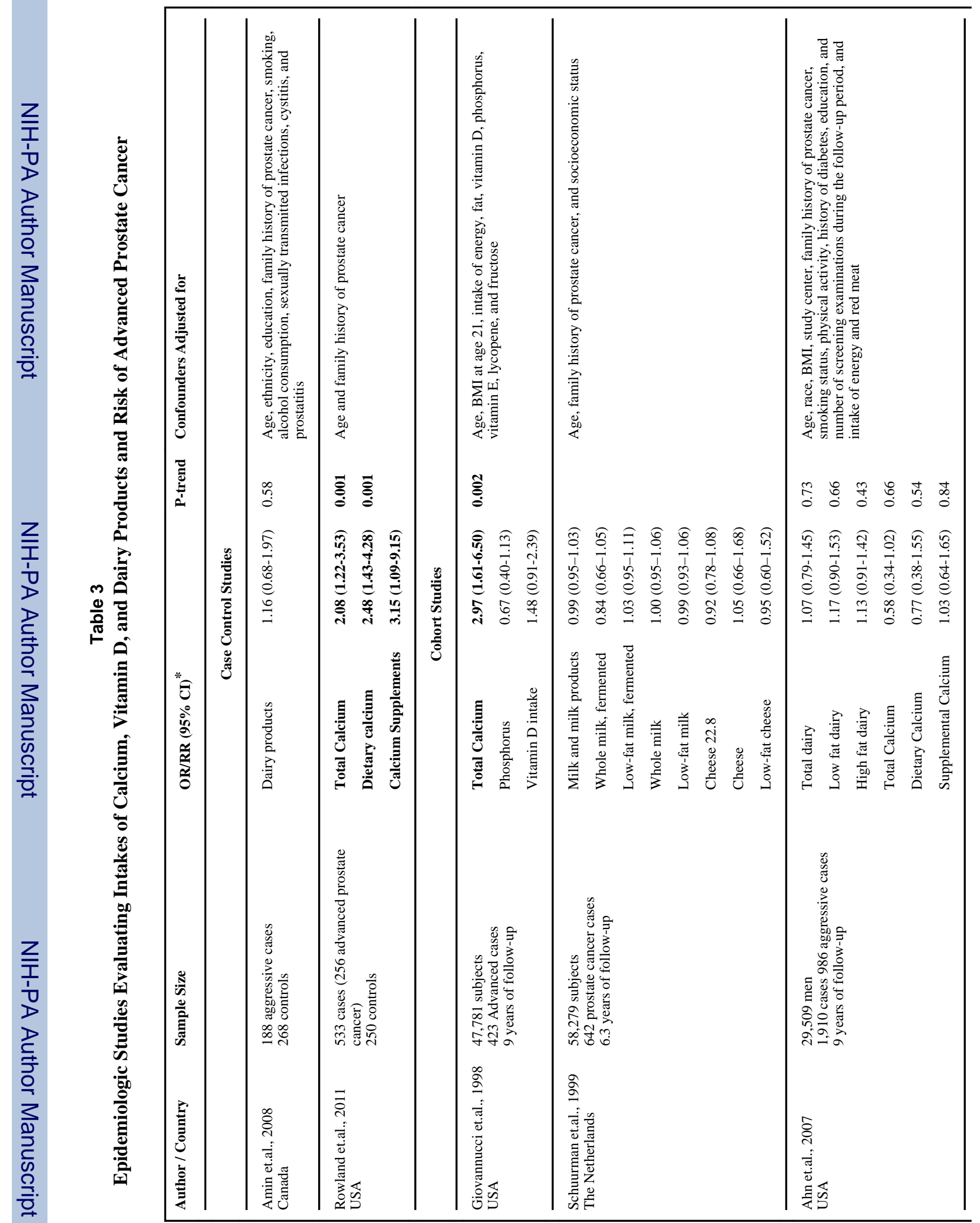

Eur J Cancer Prev. Author manuscript; available in PMC 2015 March 01. 


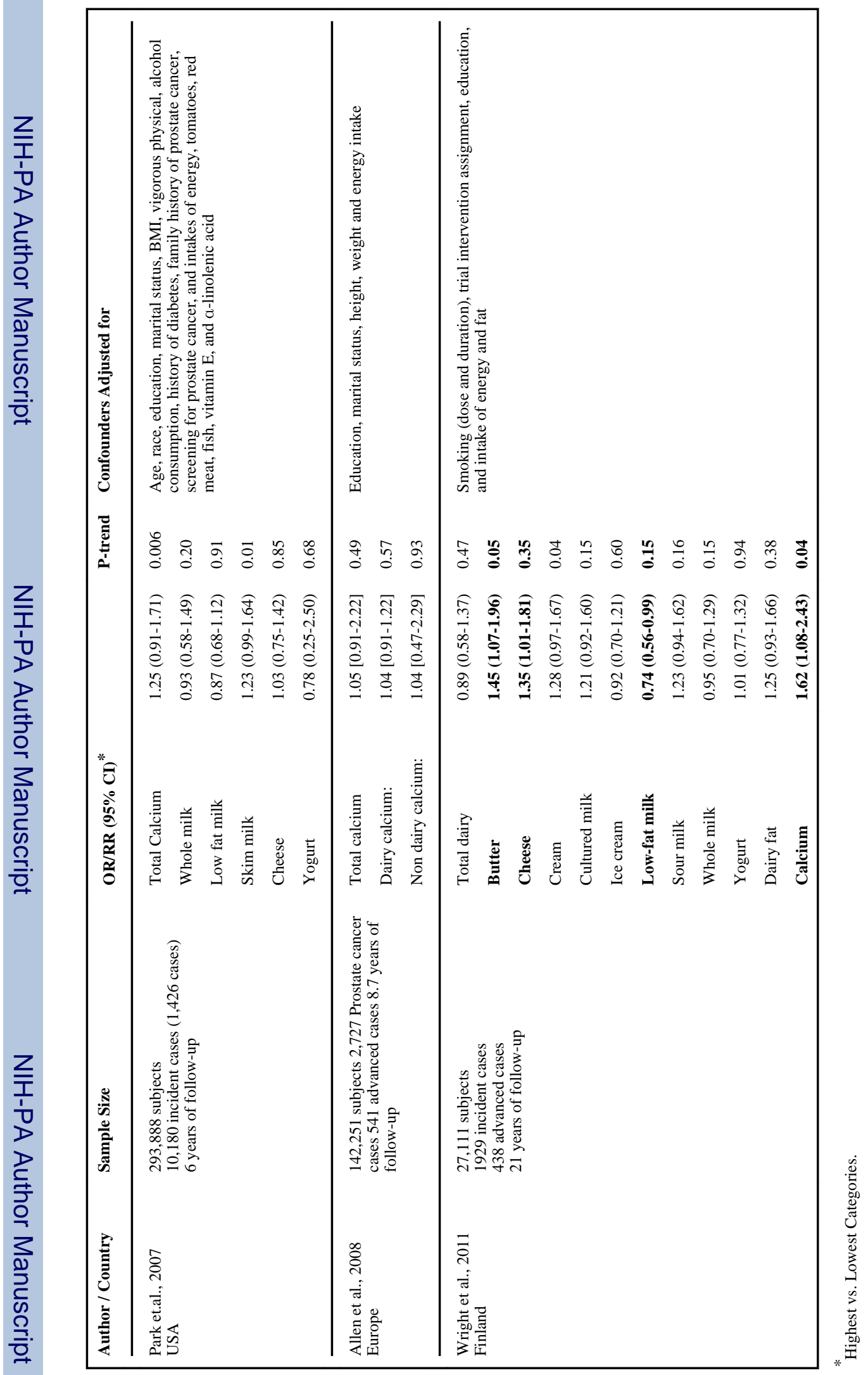

Eur J Cancer Prev. Author manuscript; available in PMC 2015 March 01. 


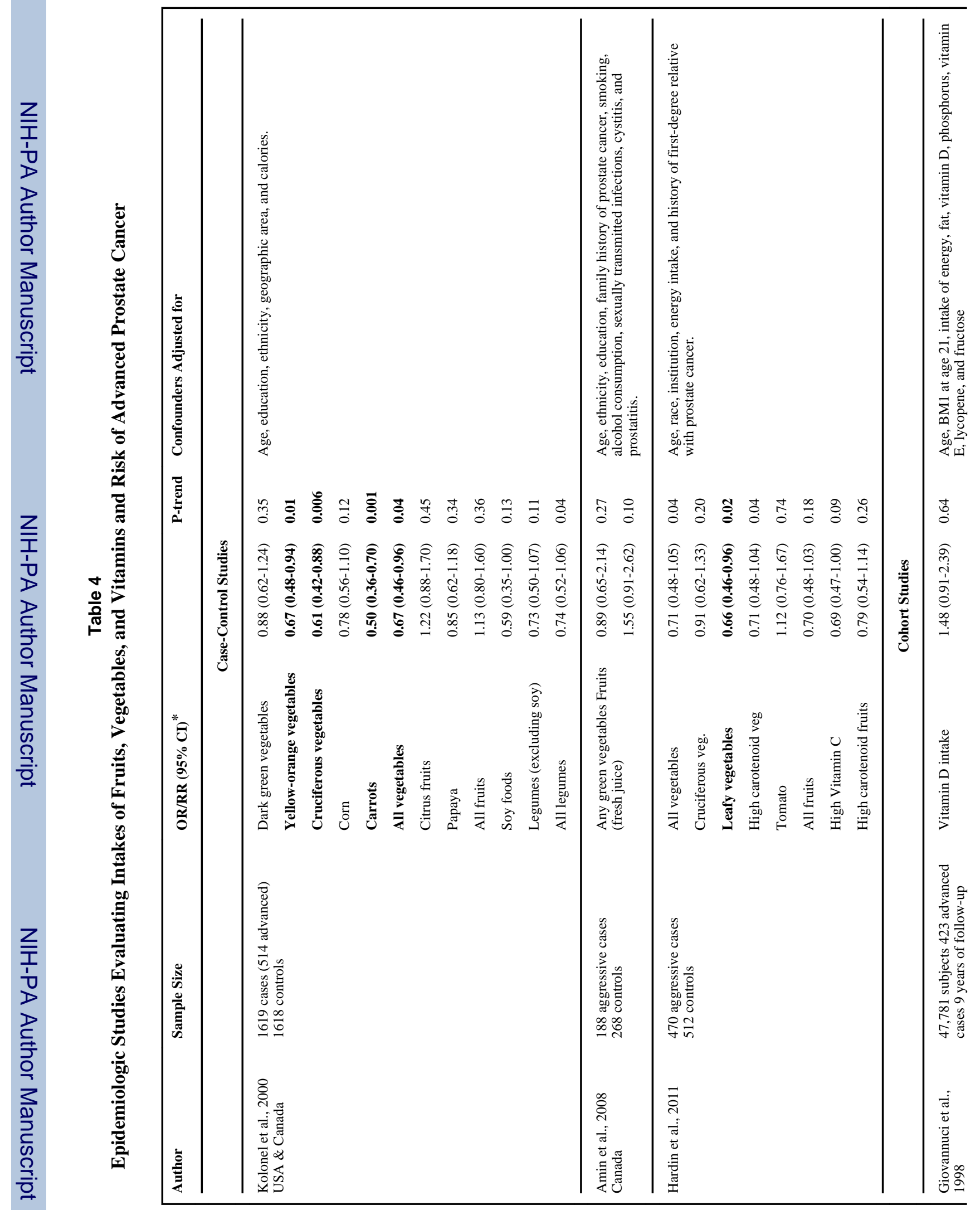

Eur J Cancer Prev. Author manuscript; available in PMC 2015 March 01. 


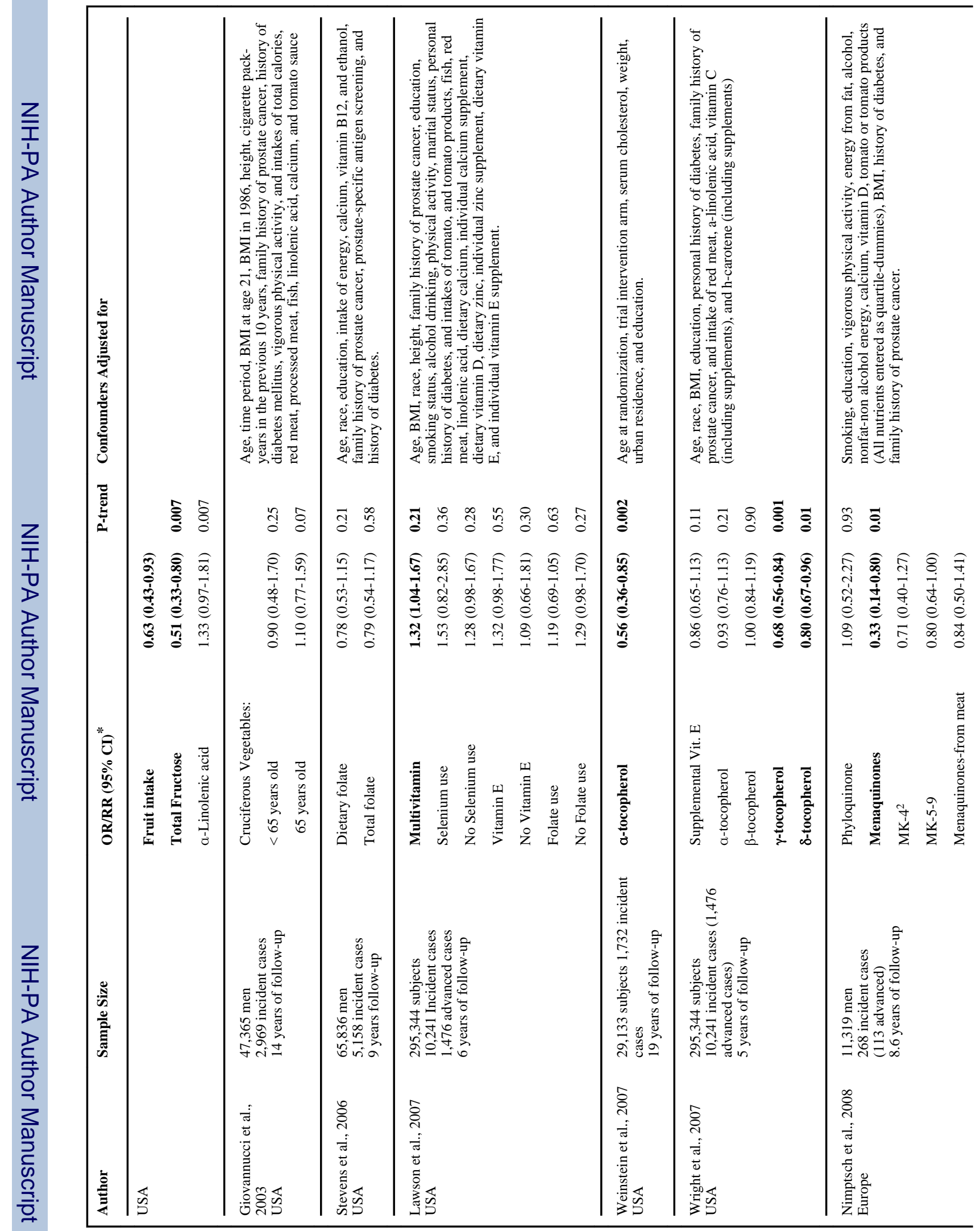

Eur J Cancer Prev. Author manuscript; available in PMC 2015 March 01. 


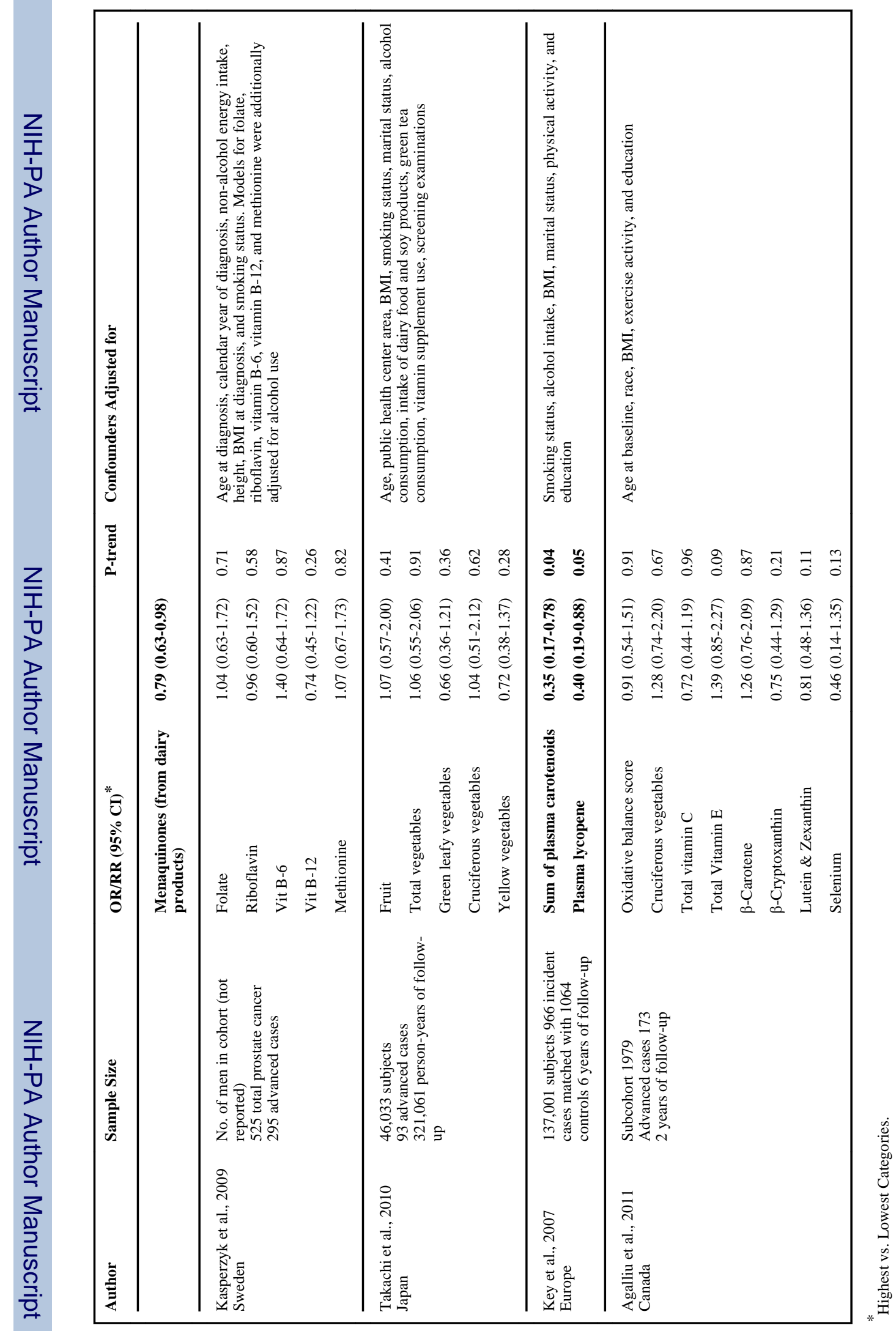

Eur J Cancer Prev. Author manuscript; available in PMC 2015 March 01. 


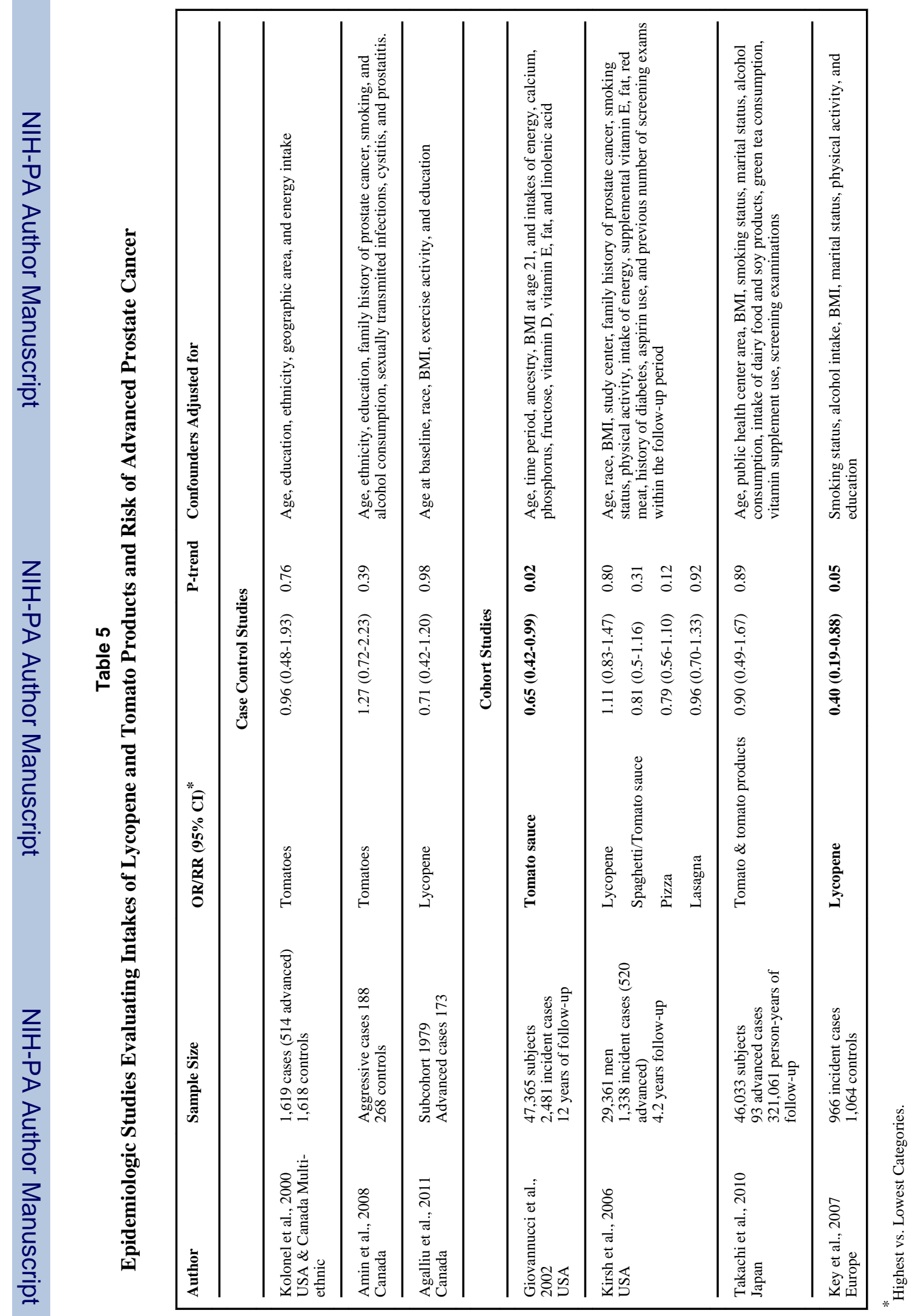

Eur J Cancer Prev. Author manuscript; available in PMC 2015 March 01. 